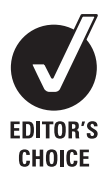

${ }^{1}$ Center for AIDS Prevention Studies, University of California, San Francisco, California, USA;

${ }^{2}$ Perinatal HIV Research Unit, University of the Witwatersrand, Johannesburg, South Africa

Correspondence to: Dr T Lane, University of California, San Francisco, Center for AIDS Prevention Studies, 50 Beale Street, 13th Floor, San Francisco, CA 94105, USA; tim.lane@ucsf.edu

Accepted 12 August 2008

\title{
"They see you as a different thing": the experiences of men who have sex with men with healthcare workers in South African township communities
}

\author{
T Lane, ${ }^{1}$ T Mogale, ${ }^{2}$ H Struthers, ${ }^{2}$ J McIntyre, ${ }^{2}$ S M Kegeles ${ }^{1}$
}

\section{ABSTRACT}

Objectives: To describe interactions between men who have sex with men (MSM) and healthcare workers (HCW) in peri-urban township communities in South Africa.

Method: Qualitative study using semistructured in-depth interviews and focus group discussions in the Gauteng province townships of Soweto and Mamelodi. $32 \mathrm{MSM}$ were purposively sampled for in-depth interviews and 15 for focus group discussions. Topics explored included identity, sexuality, community life, use of health services and experiences of stigma and discrimination.

Results: MSM felt their options for non-stigmatising sexual healthcare services were limited by homophobic verbal harassment by HCW. Gay-identified men sought out clinics with reputations for employing HCW who respected their privacy and their sexuality and challenged those HCW who mistreated them. Non-gay-identified MSM presented masculine, heterosexual identities when presenting for sexual health problems and avoided discussing their sexuality with HCW.

Conclusions: The strategies MSM employ to confront or avoid homophobia from HCW may not be conducive to sexual health promotion in this population. Interventions that increase the capacity of public sector HCW to provide appropriate sexual health services to MSM are urgently needed.

South Africa is unique among African nations for its explicit constitutional prohibition of discrimination on the basis of sexual orientation. Its major cities, including Cape Town, Durban, Johannesburg and Pretoria, are home to visible gay and lesbian communities and lesbian-gaybisexual-transgender (LGBT) community-based organisations ( $\mathrm{CBO}$ ). South Africa is also unique among African nations in that the HIV epidemic was first recognised among primarily white, gayidentified men who have sex with men (MSM) in the 1980s; only after 1990 did a second, heterosexually transmitted epidemic emerge among South Africa's black population. ${ }^{1-3}$ The national mobilisation to combat HIV has addressed heterosexual and mother-to-child transmission, whereas targeted sexual health information and services for MSM have been undertaken largely by the country's few LGBT CBO. In 2007, the South African Department of Health signalled its intention to mobilise resources to address the needs of MSM for HIV and sexual health services. The HIV and AIDS and STI Strategic Plan for South Africa 2007-2011 (NSP) recognises MSM as a specific vulnerable group, noting that "there is very little currently known about the HIV epidemic amongst
MSM" and that "MSM who practice receptive anal intercourse have an elevated risk for HIV infection". 4

The low-income, peri-urban "township" communities on the periphery of South Africa's major urban areas are home to visible, emerging communities of black MSM. In the Gauteng province townships of metropolitan Johannesburg and Tshwane (Pretoria), the population of MSM includes individuals who self-identify as "gay" or "bisexual" as well as "straight." Gay men are the most visible of MSM subgroups. The emergence of township gay communities in the years since the end of apartheid has been the subject of several studies. $^{6-9}$ Bisexual and straight-identified MSM, or non-gay-identified (NGI) MSM are often less visible, choosing to self-identify by terms that allow them to blend into the general population and that do not necessarily preclude having female sexual partners

Despite its constitution, homosexuality remains stigmatised in South Africa, as it does in much of sub-Saharan Africa, as "un-African" behaviour. ${ }^{10}$ The emergence of gay communities in townships may in turn be rendering homophobia increasingly visible in these communities. We define homophobia loosely as enacted hostility to same-sex sexuality $^{11}$ and same-sex practising individuals. ${ }^{12}$ This broad definition includes overt forms of physical assault, including rape and murder and less lethal practices, such as verbal harassment. Studies have shown that homophobia is associated with indicators of poor mental health ${ }^{13}$ and increased risk behaviour for HIV and other sexually transmitted infections (STI). ${ }^{14-16}$

In light of South Africa's unique legal framework, its severe HIV epidemic and the goals of the NSP, it is important to understand the experiences of MSM who currently access sexual health services in the public sector. Studies of sexual health-seeking behaviour among men and women in sub-Saharan Africa have observed more pronounced patterns of delayed treatment-seeking among women, ${ }^{17-19}$ and the stigmatisation of female patients' sexuality by public sector healthcare workers (HCW). ${ }^{20-22}$ However, given the persistence of stigma against homosexuality in South African society, it is worth exploring whether hostility towards same-sex practising men exists and how it impacts their sexual health-seeking strategies. In this paper we describe the experiences of Gauteng township MSM who seek public sector sexual health services. 


\section{METHODS}

We conducted in-depth interviews with 32 MSM in two Gauteng township communities (Soweto and Mamelodi) and three focus group discussions with 15 MSM in one township community (Soweto) between April 2006 and March 2007. Eligibility criteria included being 18 years of age or older and ever having had sex with another man. Although racial identity was not an explicit inclusion criterion, all participants recruited were black South Africans. Sampling began with "out" gayidentified men known to the investigators. Other gay and NGI MSM were identified through ethnographic fieldwork by $\mathrm{Mr}$ Mogale, who made repeated visits to MSM-friendly social venues in each township to establish rapport with members of MSM social networks associated with these sites. For individual interviews, we purposively sampled men based on their selfdescribed sexual identity (eg, gay, bisexual, straight, see table 1), age and reported HIV status. For each focus group discussion, we purposively recruited four gay, three bisexual and eight straight MSM to participate in a discussion with others who shared their self-described sexual identity (one discussion per identity group). All potential participants voluntarily gave their contact information to $\mathrm{Mr}$ Mogale, who arranged for study enrollment visits to take place within 2 weeks of initial contact.

Interviews took place either in a private interview room in the Perinatal HIV Research Unit (PHRU) at Chris HaniBaragwanath Hospital in Soweto, or in a private community setting of the participant's choosing. Discussions took place in a private meeting space at the PHRU. Interviews and discussions followed an interview guide that explored identity, sexuality, community life, use of health services and experiences of stigma and discrimination. Interviews lasted approximately 60 minutes and discussions approximately 120 minutes. Interviews and discussions were conducted in the participants' choice of Zulu, Sotho, Tswana or English. Written informed consent was obtained from all participants. Ethical approval was granted by the University of the Witwatersrand's Human Research Ethics Committee and the University of California, San Francisco's Committee on Human Research.

All interviews and discussions were recorded on digital voice recorders, transcribed and translated into English. Because very little research has been conducted specifically with South African MSM on the research topics, data analysis followed a grounded theory approach, allowing for in-depth exploration of emerging themes in the participants' narrative responses as research progressed. ${ }^{23}$ All English transcripts were entered into Atlas.ti software for coding. Coding took place in two phases. Topical codes were applied first to allow quotations to be sorted according to interview guide topic areas. Then, open interpretive coding was utilised to identify and analyse emerging themes within and between topical areas.

\section{RESULTS}

Participants were well informed about their right to receive HIV testing and STI treatment and where to access services. However, most participants' narratives portrayed public health

Table 1 In-depth interview participant characteristics

\begin{tabular}{llll}
\hline \multirow{2}{*}{ Township } & \multicolumn{3}{l}{ Self-described sexual identity } \\
\cline { 2 - 4 } & Gay & Bisexual & Straight \\
\hline Soweto (Johannesburg) & 10 & 3 & 5 \\
Mamelodi (Tshwane) & 13 & 1 & 0 \\
\hline
\end{tabular}

clinics as places where HCW constantly threatened MSM's rights to privacy and confidentiality by engaging in gossip and homophobic verbal harassment. All participants had either experienced or witnessed such harrassment from HCW and agreed that gay-identified men bore the brunt of HCW's homophobia. This often took the form of HCW's use of local derogatory slang words such as stabane ("hermaphrodite") and sgezo (as well as its English equivalent "faggot") to refer to openly gay patients. Indeed, those gay-identified men whose experiences of homophobia from HCW was most extreme were those who described their gender identity as being "feminine" or "like a woman" and whose speech, manners and dress were recognised as feminine by the study's fieldworker.

MSM presenting for rectal STI were particularly vulnerable to such treatment, because rectal STI were evidence that men had engaged in a particularly taboo sexual behaviour and confirmed popular stereotypes of MSM as promiscuous vectors of disease. One NGI MSM recalled an incident he witnessed between an HCW and two gay men:

"I once went to the clinic and there were two gay men at the clinic, apparently one of them had an STD, then a nurse said to them she expected that, she wasn't expecting them to have flu but an STD, because they sleep around and God is punishing them."

One gay participant attributed these experiences of harassment to what he perceived as a norm of avoiding healthcare and poor sexual health among MSM generally:

"[S]ome of them don't treat us with respect. Sometimes, if you were having sex without a condom and maybe you get an STD, then you go to the clinic, the nurse will ask questions like 'What was in here?'-she means in the anus. And that makes us afraid of going to the clinic to get treatment on time and that's why many gay men get sick."

The sexual health-seeking strategies that gay men described were built around avoiding HCW who were likely to harass them. Identifying sympathetic HCW was a difficult process of trial and error. One focus group participant expressed a preference for clinics that employed younger HCW, suggesting that homophobia was characteristic of the "ignorance" of an older generation: "We mustn't forget that most nurses are old people and they still have that mentality that a man is a man and a woman is a woman." But another disagreed, arguing that age was irrelevant, and what mattered was an HCW's capacity for acceptance, which was far more difficult to gauge from outward appearances:

\begin{abstract}
"People are aware of gay and lesbian people but accepting those people like human beings is another story, because they don't understand what they are going through inside, so that causes a problem, in terms of when you need help from them, they see you as a different thing."
\end{abstract}

Gay men did have some success in identifying non-stigmatising sexual health services, but they were not easily accessible. Among men in Soweto, two public health clinics in central Soweto and one in the Johannesburg city centre (15 km away) were mentioned as the most desirable locations for sexual health services. Participants from Mamelodi relied on one clinic in the Pretoria city centre, $25 \mathrm{~km}$ away.

However, when gay participants could not avoid homophobic HCW, they felt empowered to challenge them. One described his response to such a situation: 
"There was this one, she said to me why I am behaving like a girl and what must she write on my file, a male or a female? ... I felt bad, but I asked her how can she say that because this is who I am and it is my life, what was she going to do if I was her child? And she said she will never have a child like me! So I said she must leave me alone and do what she is here for."

Gay men who challenged HCW in this way were claiming the right to be socially visible and asserting their right as South African citizens to non-discriminatory treatment. One participant believed that the ability of gay men to receive appropriate healthcare services was improving because discrimination on the basis of sexual orientation had been outlawed. Although his optimism was not shared by other gay-identified participants, like them he situated these struggles with HCW as part of a larger, as yet incomplete, struggle for full equality:

\section{"We have cases where you find a person experiences such [negative] experiences but they are not like before. I think people are starting to have a sense of tolerance towards men of the minority groups or towards sexual orientations because of the laws of this country."}

NGI MSM in our study did not express a similar urgency to locate MSM-friendly services, or to assert their rights to nondiscrimination. Perhaps because they were more likely to witness ill-treatment of gay-identified men, their strategy was to deny their own same-sex behaviour to HCW. This was premised upon presenting a masculine gender identity to HCW and making plausible claims to heterosexual activity. As one self-identified bisexual man explained:

"I normally lie about it to them. I have a girlfriend, like if I had an STI I would tell them that my girlfriend wasn't around so I slept with somebody else and I got infected."

For NGI MSM, keeping sexuality private in healthcare settings was an extension of a larger social strategy of remaining invisible by keeping their same-sex behaviours hidden from family, friends and female sexual partners. Most felt that it was inappropriate for HCW to ask about "personal" information:

\begin{abstract}
"I struggle with trusting people. Not unless I really trust that person am I able to be open about what I do and stuff like that, because I don't think you have to be asked if you have sexually transmitted disease are you straight or gay, whether you got this from a male or female. I think that would be invading my privacy, and if someone were to ask me that it wouldn't matter how much pain I'm in I would walk out. A person must ask about the STD and how to prevent it, not personal questions like my sexual identity."
\end{abstract}

In elaborating health-seeking strategies that promoted their invisibility, NGI MSM asserted a right to privacy in healthcare that was an alternative interpretation of their constitutional guarantee of equality. But protecting privacy through invisibility also prevents many NGI MSM from seeking sexual health information and services from sympathetic public sector HCW or from LGBT CBO. For some, this could have the unintended consequence of reinforcing erroneous beliefs about HIV or STI transmission. For example, one straight-identified participant seemed certain that his STI could only be acquired heterosexually:

\footnotetext{
"I don't [disclose my same-sex behaviour] ... because when I go to the doctor is not for male sexual contact that I have contracted an STD."
}

\section{DISCUSSION}

Although the persistence of homophobia in South African society negatively impacts the ability of all MSM to access nonstigmatising health services, the specific sexual health-seeking strategies individual MSM employ to avoid homophobia depends on how they present their sexual and gender identities to HCW and how HCW perceive them. Gay-identified men, many of whom are gender non-conforming, were more likely to confront HCW homophobia in the healthcare setting when they could not access non-stigmatising health services. NGI MSM, who identified as bisexual or straight, were likely to emphasise a masculine gender identity and avoid disclosing same-sex sexual behaviour when presenting for sexual health services. The split between gay and NGI MSM's experiences with HCW appears to follow the gendered construction of STI in South Africa described by Shefer et $a l^{21}$ by which HCW stigmatise the sexuality of women who contract STI as "promiscuous", but not men, who may sometimes receive positive reinforcement about their presumed multiple partnerships from HCW as well as their peers. With MSM in this study, the sexuality of openly gay-identified and gender non-conforming men was further stigmatised by HCW's homophobia; knowing this, NGI MSM who were not open about their sexuality and were able to emphasise their masculinity could escape such degrading and "feminising" treatment.

Goal 16.3 of South Africa's NSP is to "Ensure a supportive legal environment for the provision of HIV and AIDS services to marginalised groups" and to "Develop and distribute information and materials on rights to HIV prevention, treatment and support that responds to the special needs of ... MSM."4 This is an important goal that must be pursued in the light of South Africa's constitutional guarantees of non-discrimination. However, the experience of MSM in this study was not simply a lack of information about the right to healthcare; rather, that access to sexual healthcare in the public sector was complicated by the perception, based on actual experience, that they are likely to encounter homophobic verbal harassment from HCW. As one participant suggested, HCW homophobia may lead MSM to delay or avoid treatment for STI or HIV. It may also be the case that only exceptionally self-confident gay-identified men who are knowledgeable about the larger struggle for LGBT equality in South Africa are able to confront homophobia in healthcare settings. Yet the enmity gay men incur by defending themselves is not conducive to forming patient-provider relationships that encourage the adoption of health-promoting behaviours. Further research should explore these hypotheses.

Although experiences of homophobia among NGI MSM were less direct or severe than gay men's, their strategy of not discussing same-sex behaviour with HCW may place them at a greater disadvantage than "out" gay men in their ability to access appropriate advice on STI and HIV prevention and treatment. LGBT $\mathrm{CBO}$ reach out to openly gay-identified men, and many NGI MSM may feel uncomfortable accessing services that are associated with gay men. Therefore, NGI MSM who avoid these services and act on the assumption that public sector HCW are hostile to same-sex sexuality effectively deny themselves any source of appropriate HIV and STI prevention information. It is uncertain how widespread these experiences are, but it may be the case that NGI MSM's strategy of avoiding homophobia in healthcare settings inadvertently causes these MSM to continue to compromise their own sexual health as well as the health of their male and female partners.

These findings have important implications for intervention. Promoting awareness of sexual health services for MSM must be 


\section{Key messages}

- At present, South African men who have sex with men (MSM) have limited access to non-stigmatising sexual health services.

- Many gay-identified MSM experience homophobic verbal harassment from healthcare workers when presenting for STI treatment.

- To avoid harassment, many NGI MSM will deny or avoid discussing their smae-sex behaviour with healthcare workers.

accompanied, at a minimum, by sensitisation training for public sector HCW. This training needs to increase HCW awareness of the sexual health challenges that all same-sex practising men face. HCW will need to build skills that encourage and enable them to offer non-stigmatising sexual health and HIV services to gender non-conforming MSM. In addition, it should increase HCW awareness that not all MSM identify as gay, or are gender non-conforming and that NGI MSM may be reluctant to discuss their same-sex behaviours. Such an intervention would not by itself remove homophobia from public health services, but by affirming a commitment to non-discrimination on the basis of sexual orientation, it would be an important step towards ensuring a supportive environment for all South Africans seeking sexual health services. South Africa's LGBT $\mathrm{CBO}$ and health professionals can provide valuable assistance to these efforts. In addition, the efforts of LGBT CBO to provide sexual health services for MSM and to identify and develop networks of "gay-friendly" health service providers should be strengthened and expanded.

This study has several limitations. This research was explicitly focused on the experiences of MSM in two communities in a single South African province and may not be generalisable to the entire country. However, Gauteng is the wealthiest, most urban and most cosmopolitan of South Africa's provinces, where an LGBT CBO is active in promoting LGBT rights in township communities, including rights to sexual healthcare and HIV prevention and treatment. It is possible that the visibility and assertiveness of LGBT persons in Gauteng elicits strong homophobic reactions among a minority of HCW; but it is also possible that these experiences may represent the best-case scenario for South African township MSM at present. While the research team made every effort to recruit MSM from all known MSM subgroups, our sampling methodology favoured the recruitment of gay men and a smaller number of bisexual and straight MSM who were comfortable discussing their sexuality and social lives. All participants were probably more knowledgeable about accessing health services and comfortable with the risks of participating in socially sensitive research than others in their communities or in South Africa more generally. Nonetheless, the evidence presented here suggests that MSM who are less socially visible or comfortable discussing sexuality would have particular difficulty accessing appropriate healthcare. Finally, this research did not directly address the experiences of HCW in meeting the sexual healthcare needs of MSM, which would be an important component of the development of a comprehensive and effective strategy to combat homophobia in the health services.

The South African constitution's prohibition of discrimination on the basis of sexual orientation provides a necessary precondition for realising the NSP's goal of increasing awareness of the rights of all South Africans to HIV and STI prevention and treatment. However, these findings suggest that a focus solely on increasing awareness is insufficient. Gay-identified men seem well aware of their rights—and that their rights are being violated - whereas few NGI MSM seem inclined to claim or enforce their rights. MSM's collective experiences suggest an urgent need for HCW to be made aware of the rights of all MSM to non-stigmatising sexual health services and receive training that more appropriately equips them to care for all same-sex practising individuals.

Funding: This research was supported by the National Institute of Mental Health (NIMH), grant $\mathrm{K} 01 \mathrm{MH} 074369$.

Competing interests: None.

Ethics approval: Ethics approval was granted by the University of the Witwatersrand's Human Research Ethics Committee and the University of California, San Francisco's Committee on Human Research.

Patient consent: Obtained.

\section{REFERENCES}

1. Puren AJ. The HIV-1 epidemic in South Africa. Oral Dis 2002:8(Suppl 2):27-31.

2. Maartens G, Wood R, O'Keefe E, et al. Independent epidemics of heterosexual and homosexual HIV infection in South Africa-survival differences. $0 \mathrm{~J}$ Med 1997:90:449-54.

3. van Harmelen J, Wood R, Lambrick M, Rybicki EP, et al. An association between HIV-1 subtypes and mode of transmission in Cape Town, South Africa. AIDS 1997;11:81-7.

4. Department of Health. HIV and AIDS and STI National Strategic Plan for South Africa 2007-2011. South Africa: Department of Health, 2007.

5. Lane T, Shade S, Mclntyre J, et al. Alcohol and sexual risk behavior among men who have sex with men in South African township communities. AIDS Behav 2008;12(Suppl 1):78-85

6. McLean H, Ngcobo L. Abangibhamayo bathi ngimnandi (Those who fuck me say I'm tasty): Gay sexuality in Reef townships. In: Gevisser M, Cameron E, eds. Defiant desire: gay and lesbian lives in South Africa. New York: Routledge, 1995:158-85.

7. Donham D. Freeing South Africa: the 'modernization' of male-male sexuality in Soweto. Cultural Anthropol 1998;13:3-21.

8. Graziano KJ. Oppression and resiliency in a post-apartheid South Africa: unheard voices of Black gay men and lesbians. Cultur Divers Ethnic Minor Psychol 2004;10:302-16.

9. Spruill J. Ad/dressing the nation: drag and authenticity in post-apartheid South Africa. J Homosex 2004:46:91-111.

10. Epprecht M. Black skin, 'cowboy' masculinity: a genealogy of homophobia in the African nationalist movement in Zimbabwe to 1983. Cult Health Sex 2005;7:253-66.

11. Altman D. HIV, homophobia, and human rights. Health Hum Rights 1998:2:15-22

12. Johnson C. Off the map: how HIV/AIDS programming is failing same-sex practising people in Africa. New York: International Gay and Lesbian Human Rights Commission, 2007.

13. Diaz RM, Ayala G, Bein E, et al. The impact of homophobia, poverty, and racism on the mental health of gay and bisexual Latino men: findings from 3 US cities. Am J Public Health 2001;91:927-32.

14. Diaz RM, Ayala G, Bein E. Sexual risk as an outcome of social oppression: data from a probability sample of Latino gay men in three U.S. cities. Cultur Divers Ethnic Minor Psychol 2004; 10:255-67.

15. Preston DB, D'Augelli AR, Kassab CD, et al. The influence of stigma on the sexual risk behavior of rural men who have sex with men. AIDS Educ Prev 2004;16:291-303.

16. Preston DB, D'Augelli AR, Kassab CD, et al. The relationship of stigma to the sexual risk behavior of rural men who have sex with men. AIDS Educ Prev 2007:19:218-30.

17. Voeten HA, O'Hara HB, Kusimba J, et al. Gender differences in health care-seeking behavior for sexually transmitted diseases: a population-based study in Nairobi, Kenya. Sex Transm Dis 2004;31:265-72.

18. Fonck K, Mwai C, Rakwar J, et al. Healthcare-seeking behavior and sexual behavio of patients with sexually transmitted diseases in Nairobi, Kenya. Sex Transm Dis 2001:28:367-71.

19. Moses S, Ngugi EN, Bradley JE, et al. Health care-seeking behavior related to the transmission of sexually transmitted diseases in Kenya. Am J Public Health 1994;84:1947-51

20. Nuwaha F. Determinants of choosing public or private health care among patients with sexually transmitted infections in Uganda. Sex Transm Dis 2006;33:422-7.

21. Shefer T, Strebel A, Wilson T, et al. The social construction of sexually transmitted infections (STIS) in South African communities. Oual Health Res 2002;12:1373-90.

22. Ndulo J, Faxelid E, Tishelman C, et al. "Shopping" for sexually transmitted disease treatment: focus group discussions among lay persons in rural and urban Zambia. Sex Transm Dis 2000:27:496-503.

23. Strauss A, Corbin J. Grounded theory methodology: an overview. In: Denzin N, Lincoln Y, eds. Strategies of qualitative inquiry. Thousand Oaks, CA: Sage, 1998:158-83. 